\title{
SISTEMA INTERNACIONAL DE COMÉRCIO E DIREITO AO DESENVOLVIMENTO: COEXISTENTES OU ANTAGÔNICOS?
}

\author{
Beatriz Figueiredo Campos da Nóbrega \\ Graduada em Tecnologia em Comércio Exterior pelo Instituto Federal do Rio Grande do \\ Norte. Graduanda em Bacharel em Direito pela UFRN. \\ E-mail: beatriznobreg@ hotmail.com \\ Elisângela Cabral de Meireles \\ Graduada em Ciências Econômicas-UFRN, esp. em Economia Regional, Comércio \\ Exterior e Globalização-UFRN, mestre em Administração (Gestão e Políticas Públicas) \\ UFRN, Professora do IFRN (Comércio Exterior e Economia) e Professora Orientadora da \\ Base de Pesquisa "Análise do Mercado Exportador do Rio Grande do Norte (IFRN). \\ E-mail- elisangela@cefetrn.br
}

\section{SISTEMA INTERNACIONAL DE COMÉRCIO E DIREITO AO DESENVOLVIMENTO: COEXISTENTES OU ANTAGÔNICOS?}

\begin{abstract}
RESUMO
Compreender a lógica do Sistema Internacional de Comércio (SIC) e sua correlação com o Direito ao Desenvolvimento: eis o fulcro deste projeto. O sustentável desempenho do SIC depende da garantia do Direito ao Desenvolvimento a cada nação. Este, por sua vez, só será adequada e efetivamente concretizado se conjugado a uma dinâmica comercial internacional norteada conforme a igualdade real entre as nações. Deste modo, deve-se buscar adequar a lógica das relações comerciais hodiernas ao necessário desenvolvimento justo e democrático das nações. Mas como concretizar tal anseio no âmbito prático, não o restringindo ao campo meramente teorético? Ou, ainda, como conciliar a realidade atual das relações internacionais comerciais com a efetivação do Direito ao Desenvolvimento? Neste sentido, o presente escrito foi estruturado para fins de se perquirir a inter-relação entre comércio e desenvolvimento e suas implicações, perpassando pelas respectivas construções teóricas e culminando na avaliação de sua vigência prática na conjuntura moderna. Para tanto, foi realizada ampla pesquisa bibliográfica, de cunho exploratóriodescritiva, de fontes nacionais bem como internacionais - dada a amplitude e extensa repercussão do tema em foco -, centrada em dados secundários que caracterizam-na como quali-quantitativa.
\end{abstract}

Palavras-chave: Sistema Internacional de Comércio. Direito ao Desenvolvimento. Relações Internacionais.

\section{THE INTERNATIONAL TRADE SYSTEM AND THE RIGHT TO DEVELOPMENT: COEXISTING OR ANTAGONICS?}

\begin{abstract}
To understand the reasoning of International Trade System (ITS) and its correlation with the Right to Development: this is the fundamental purpose of this project. The sustainable performance of the ITS depends on the guaranty of the Right to Development to every nation. This right, by its means, will only be proper and effectively achieved if conjugated to an international trade dynamic compliant to a real equality among nations. In this
\end{abstract}


manner, the adjustement of the hodiernal trade relations according to the necessary, fair and democratical development of the nations is vital. Neverthless, how to fulfill this aim in practical means, not restricting it to the mere theoretical field? Or, still, how to conciliate the present reality of the international trade relations with the implementation of the Right to Development? Thus, the present essay was writen in order to examine the connection between trade and development, going through the respective theories and resulting in the evaluation of its practical existence at the modern conjuncture. Towards this intent, it was accomplished ample bibliographical research, through national and internacional resources - given the extension and wide repercussion of the analysed theme - based on secondary data, which defines it as a quality-quantity study.

Key words: International Trade System. Right to Development. International Relations.

\section{SISTEMA INTERNACIONAL DE COMÉRCIO E DIREITO AO DESENVOLVIMENTO: COEXISTENTES OU ANTAGÔNICOS?}

\section{INTRODUÇÃO}

Para suprir as necessidades inerentes a cada organização nacional, recorre-se ao Sistema Internacional de Comércio, por meio do qual bens e serviços são trocados através das fronteiras internacionais.

O comércio internacional representa o mais antigo elo entre as nações, fomentando as relações internacionais a partir do intercâmbio das hipossuficiências mútuas. Além de promover a integração entre os Estados, incrementa a união e a troca de interesses entre estas, de modo a se poder afirmar que, sem comércio, não há crescimento de uma nação.

Neste conduto, o comércio internacional apresenta, pois, adjacentes efeitos incidentes não apenas sobre o setor econômico, mas também sobre o social, cultural e político, de modo a envolver uma gama de interesses públicos, difusos e coletivos, a ponto de não se poder negar sua decisiva influência sobre o fator desenvolvimento. Seu crescimento ${ }^{1}$, potencializado pelo processo de globalização econômica e a conseqüente internacionalização do capital, vem fomentando o aumento da interdependência entre as nações. De fato, verifica-se, hoje, uma crescente vinculação dos países subdesenvolvidos frente às determinações e políticas adotadas pelos nominados "desenvolvidos".

Enquanto corolário de dita tendência, surge verdadeira afronta à soberania política interna a cada Estado, sobre a qual incidem, de forma mais concreta, os efeitos da globalização por sobre a governança dos Estados. Sob esta égide, a soberania apresenta-se como a prerrogativa de independência de fato que um Estado apresente perante as demais nações o que variará conforme o grau de integração econômica ou militar, o sistema de blocos regionais que integre e mesmo a força de decisão própria do Estado individualmente considerado.

\footnotetext{
${ }^{1} \mathrm{O}$ comércio internacional cresceu nos últimos cinqüenta anos em níveis sem precedentes. As trocas comerciais internacionais representavam 14\% do PIB mundial em finais do século XX (2000). Em 1950, o percentual do PIB mundial representado pelo comércio internacional chegava a $6 \%$. A explosão do capital móvel, a revolução da informação e as pressões demográficas, que demandam um nível de consumo maior são alguns dos fatores responsáveis por esse incremento na atividade comercial internacional. (MARCJOHNSON, 2001, p. 288).
} 
Prevalece, hoje, tendência contínua à configuração de uma ordem econômica mundial pautada por autêntica sujeição, no âmbito das relações internacionais, de determinados países perante outros, de forma que o capital tem determinado os rumos da política dos países submissos - dinâmica esta que, por conseguinte, vem moldando uma crescente subordinação política de certos Estados a outros no sistema capitalista mundial, dada a limitação da capacidade de decisões políticas autônomas diante de sua impotência perante a dependência econômica.

Diante desta conjuntura, surge a problemática do presente escrito. O sustentável desempenho do Sistema Internacional de Comércio depende da garantia do Direito ao Desenvolvimento às nações. Este, por sua vez, só será adequada e efetivamente garantido se conjugado a uma política de não-discriminação. Deste modo, deve-se buscar adequar a lógica das relações comerciais hodiernas ao necessário desenvolvimento justo e equânime das nações. Mas como concretizar tal anseio formal no âmbito prático, não o restringindo ao campo meramente teorético? Ou, ainda, como conciliar a realidade atual das relações internacionais comerciais com a efetivação do Direito ao Desenvolvimento?

Compreender a relação entre o Sistema Internacional de Comércio e a efetivação do Direito ao Desenvolvimento, enquanto direito de terceira geração - direito de titularidade coletiva atribuído genericamente a todas as formações sociais, que se consagra, portanto, como valor fundamental indisponível - afigura-se como objetivo precípuo desta pesquisa.

\section{DA INTER-RELAÇÃO ENTRE O SISTEMA INTERNACIONAL DE COMÉRCIO E O DIREITO AO DESENVOLVIMENTO}

Alcançar um pleno e efetivo Direito ao Desenvolvimento: nisto reside um dos maiores desafios do século XXI. Confirmada pelas desigualdades sócio-econômicas persistentemente vigentes no mundo hodierno, tal constatação reflete os obstáculos que a instituição de um Sistema Internacional de Comércio fundado em bases justas e equânimes enfrenta a fim de fazer prevalecer uma real e autêntica multilateralização de privilégios no âmbito das transações comerciais verificadas em âmbito internacional.

Dada a decisiva influência que o fator desenvolvimento apresenta sobre a forma e prossecução das relações econômicas entre as nações, o direito à sua efetivação deve ser continua e progressivamente assegurado a fim de se obter uma autêntica implementação de um tal Sistema pautado por princípios de não-discriminação.

\section{DO DIREITO AO DESENVOLVIMENTO}

A origem do desenvolvimento enquanto direito normativamente assegurado remonta à Carta da ONU de 1945 (preâmbulo e artigo 1.3). Pode-se, contudo, observar que suas bases são, de fato, anteriores à Carta de São Francisco - noção esta corroborada pela Declaração da Filadélfia da Organização Internacional do Trabalho (OIT), que data de 1944 e que já 
expressava que todos os homens: "tienen el derecho tanto al bienestar material como al desarrollo espiritual, en condiciones de libertad y dignidad, de seguridad económica y de igualdad de oportunidades",2. No entanto, é só no ano de 1986 que esse direito foi formal e mundialmente conclamado ${ }^{3}$ - momento a partir do qual ele passa a ser exigível, simultaneamente, como direito individual do ser humano e como direito coletivo inerente a todo e qualquer povo, cabendo aos Estados elaborar e implementar políticas públicas capazes de garantir a real concretização de tal direito, tanto no plano interno como no internacional, bem como assegurando sua efetividade presente e futura.

O desenvolvimento consiste em um processo (PINTO, 1959, p. 32). Excedendo esta definição teórica, pode-se, ainda, afirmar que reflete ele um processo de caráter dinâmico que foi tendo seu conceito modificado conforme a evolução histórica das relações internacionais. Inicialmente restrito ao campo econômico, o desenvolvimento incorporou, aos poucos, matizes das demais disciplinas, tornando-se, portanto, produto de um processo cumulativo que se irradia por áreas diversas da mutante vida em sociedade. Amartya Sen respalda este raciocínio ao declarar que "é difícil pensar que o desenvolvimento possa realmente ser visto independentemente de seus componentes econômicos, sociais, políticos ou jurídicos"(SEN, 2005).

Tal multidisciplinariedade evidencia-se, ainda, na própria Declaração Sobre o Direito ao Desenvolvimento (DDD) de 1986, que dispõe, já em seu preâmbulo, que:

[...] o desenvolvimento é um processo econômico, social, cultural e político abrangente, que visa o constante incremento do bem-estar de toda a população e de todos os indivíduos com base em sua participação ativa, livre e significativa no desenvolvimento e na distribuição justa dos benefícios daí resultantes (DECLARAÇÃO SOBRE O DIREITO AO DESENVOLVIMENTO, 1986, preâmbulo)

A fim de se alcançar este objetivo, deve-se, então, conservar a análise interdisciplinar dos problemas e desafios enfrentados pelo corpo social, da mesma forma que devem ser considerados os princípios presentes na Carta da Organização das Nações Unidas; os dispositivos da DDD, da Declaração Universal dos Direitos Humanos, do Pacto Internacional sobre Direitos Econômicos, Sociais e Culturais, do Pacto Internacional sobre Direitos Civis e Políticos; além de importantes documentos das Nações Unidas e de suas agências especializadas que reafirmam o direito de o homem desfrutar de desenvolvimento integral, bem como de progresso econômico e social.

Além dos preceitos de tais documentos, é indispensável manter em mente, ainda, o direito dos povos à autodeterminação; ao exercício de soberania total sobre suas riquezas e recursos naturais; às liberdades fundamentais - sem qualquer distinção relativa à raça, sexo,

\footnotetext{
2 Tradução livre:[todos os homens] "têm direito tanto ao bem estar material como ao desenvolvimento espiritual, em condições de liberdade e dignidade, de segurança econômica e de igualdade de oportunidades".

3 A primeira menção à existência de um direito ao desenvolvimento, em um documento internacional de ampla aceitação entre os Estados, dá-se com a Declaração Sobre o Direito ao Desenvolvimento (DDD), de 1986.
} 
língua ou religião -; à supressão de injustiças provocadas por situações nas quais a violação dos direitos humanos se fez evidente e marcante - tais como o colonialismo, neocolonialismo, o apartheid e demais formas de atentados contra a integridade dos povos -; bem como à paz e segurança internacionais, pressupostos de fato à realização plena do direito ao desenvolvimento.

\section{SISTEMA INTERNACIONAL DE COMÉRCIO}

O comércio vigora, desde a remota Antiguidade, como o mais forte elo entre as nações, atuando como fomentador da integração, troca e união entre estas. Com efeito, a estruturação de um tal sistema encontra respaldo filosófico-doutrinário, teorizando-se, há muito, acerca da correlação entre comércio e paz internacional. Neste conduto, tem-se a obra de Kant, que, em "A Paz perpétua", delineia o comércio enquanto sendo um importante instrumento passível de conduzir a comunidade internacional a um estado de efetiva paz eterna - vez que, no nível intersocietal, defendia a "arte do comércio" como medida substitutiva às modalidades bélicas de outrora, sugerindo a construção de uma Liga Mundial, que, ao inaugurar uma interdependência natural entre os países, consolidaria a união em torno de interesses comuns de proteção, defesa e, principalmente, comércio.

Kant previu, ainda, a existência de um "espírito do comércio" ("Handelsgeist"), que, inerente às práticas comerciais, afastaria a tendência das nações à guerra e, portanto, a um estado conflituoso perene (KANT, 2002, p. 148-149).

Neste diapasão, Montesquieu também converge à linha de filósofos propagadores de uma visão otimista e positiva do comércio internacional, estruturando uma correlação necessária entre o comércio e a democracia, ao negar a compatibilidade do comércio com a tirania, vez que, apenas em uma sociedade democrática seria possível que o comércio atingisse seus fins de distribuição democrática de ganhos e benefícios (MONTESQUIEU, 1982, p. 359). Igualmente, o sábio francês prevê, como conseqüência natural do comércio, o alcance as paz (MONTESQUIEU, 1982, p. 335).

De fato, outra doutrina também merece menção, qual seja a literatura keynesiana. John Maynard Keynes, buscando um aprimoramento do sistema capitalista, que se mostrara falível com a Queda da Bolsa de Nova Iorque, em 1929, defendia uma maior intervenção estatal na economia, dado considerar a incerteza como fator endógeno nesta interveniente e que, por conseguinte, implicava deficiências na estrutura de um livre mercado, vez que desprovido de regulamentações capazes de garantir uma segurança e efetividade econômicas. Sob este conceito, Keynes propôs, no ano de 1942, um sistema de comércio internacional pautado pelo pleno emprego e a concretização dos direitos sociais, acreditando ser "sobre fronteiras não cruzadas por mercadorias que soldados acabam cruzando" (SOUSA, apud BARRAL; PIMENTEL, 2006).

\footnotetext{
${ }^{4}$ Em sua obra "A Paz Perpétua", breve ensaio publicado em 1795, Kant propôs o clássico modelo de Federalismo Mundial, segundo o qual buscava alertar os homens para a necessidade da paz definitiva entre os Estados. Segundo o iluminista, as coletividades estatais deveriam pactuar o término dos conflitos, em sentido análogo ao que faziam os indivíduos ao se unirem contratualmente para fins de constituição da sociedade civil. Tratava-se, outrossim, de verdadeiro imperativo categórico estatal, uma colaboração para o grandioso projeto moral de construção jurídica da nova comunidade internacional. (KANT, 2002).
} 
Os fluxos comerciais que configuram o chamado Sistema Internacional de Comércio afiguram-se, de fato, como potenciais instrumentos de pacificação das relações internacionais, na medida em que podem, efetivamente, ser utilizados no sentido de fomentar e impulsionar tratos amistosos entre as nações.

Com efeito, reforçando a faceta benéfica do comércio internacional, este apresenta como vantagens eminentes, além da criação de vínculos amicais entre as nações, o aumento da produtividade nacional; maiores ganhos de escala; alargamento do mercado consumidor; eliminação da sazonalidade pela abertura ao mercado externo; potencialização das oportunidades de investimentos; desenvolvimento tecnológico; imagem nacional destacada, favorecendo a competitividade nacional; aprimoramento da qualidade dos serviços e produtos nacionais; melhor utilização do parque industrial instalado; geração de renda e divisas para o país; bem como transformação setorial no quadro do comércio, pelo que se verifica um aumento de produtos de alta tecnologia e uma diminuição de produtos primários, dada a crescente concorrência entre os exportadores pela produção de produtos continuamente mais competitivos, fomentada pelo aprendizado e especialização de novas tecnologias.

Não obstante, essa visão idílica do sistema internacional de comércio, posto que restrita as suas proficuidades, revela-se débil e insuficiente ao contorno de sua real configuração. Intrinsecamente, tal sistema tende, por outro lado, à geração de conflitos e tensões. A lógica capitalista de maximização do lucro e de obtenção de vantagens econômicas a qualquer custo tem conduzido tal sistema a uma dicotômica realidade na qual coexistem, conflituosamente, a proteção à produção interna pelos Estados e a consequente adoção de barreiras protecionistas nacionais, de um lado, e a efetivação de um comércio internacional pautado em bases justas, equânimes e promotor do desenvolvimento individual das nações, de outro.

A conjuntura político-econômica atual revela, em efetivo, a real dificuldade de superação deste conflito, vez que a expansão comercial tem se encaminhado no sentido de potencialização do poderio e influência dos países mais economicamente poderosos por sobre os demais, de modo que seus interesses findam por prevalecer, antidemocraticamente, na dinâmica econômica internacional. Assim, os chamados Países Em Desenvolvimento (PEDs) e os Países Menos Desenvolvidos (PMDs) vêem limitada sua capacidade de formulação de políticas públicas, de modo que a flexibilidade e implementação de políticas econômicas autônomas se revela francamente restringida - ao que se segue, naturalmente, a defasagem desenvolvimentista sofrida por estes países, cujo âmbito de condução de medidas adequadas à resolução de deficiências peculiares à sua própria estrutura institucional resulta prejudicada.

\section{A PROPÓSITO DA RELAÇÃO ENTRE O DIREITO AO DESENVOLVIMENTO E O SISTEMA INTERNACIONAL DE COMÉRCIO}

A vinculação entre o Direito ao Desenvolvimento e o comércio internacional fundamentase, precipuamente, na dependência que a efetividade daquele mantém quanto a relações comerciais internacionais realizadas em patamares justos e equânimes, livres das amarras 
imperialistas de outrora - tendo-se em vista que as transações comerciais são, em verdade, bojo de manutenção da sobrevivência econômica das nações.

De fato, nenhuma nação é absolutamente auto-suficiente. Para suprir as necessidades inerentes a cada organização nacional, recorre-se ao sistema internacional de comércio por meio do qual bens e serviços são trocados através das fronteiras internacionais.

Assim teorizado, o comércio internacional aparenta ser um processo aparentemente simples. Contudo, ele oculta um sem-número de implicações e conseqüências que afetam desde o setor econômico ao social, cultural e político - não se podendo negar, então, sua decisiva influência sobre $\mathrm{o}$ fator desenvolvimento, dotada da supramencionada multidisciplinariedade.

Com seu crescimento potencializado pelo processo de globalização e o conseqüente aumento do fluxo de capitais entre as economias, a vertente internacional das relações comerciais vem sendo responsável pelo aumento da interdependência entre as nações. No entanto, contrariamente ao esperado, não se obteve, com isso, a almejada redução das disparidades entre os membros de tal comércio ${ }^{5}$, de modo que a miséria não foi substancial nem muito menos igualitariamente mitigada. Do contrário, vem se verificando uma crescente dependência dos países em desenvolvimento, notadamente quanto aos investimentos feitos pelos desenvolvidos - o que, de certa forma, contribui para assemelhar o sistema internacional de comércio atual à Divisão Internacional do Trabalho (DIT) típica do período colonial, visto que aqueles continuam exportando majoritariamente matériaprima, enquanto estes industrializam-na.

O modelo atual de comércio internacional vem, portanto, demonstrando-se um verdadeiro entrave no que tange à efetivação do direito ao desenvolvimento ${ }^{6}$. Cientes de tal realidade, a Organização das Nações Unidas (ONU) vem então buscando atuar de forma a identificar e suprimir as razões ensejadoras de tal obstáculo, como perceber-se-á da leitura do tópico seguinte. Efetivamente, um de seus grupos de trabalho admitiu, já em 1994ㄹ, a globalização da economia mundial - e, pois, a intensificação do comércio mundial, posto que seu corolário - como fenômeno motivador de novas barreiras ao direito ao desenvolvimento, máxime por sua determinante influência frente à restrição do poder de ação dos governos na elaboração de suas políticas econômicas, bem como na adequação destas às necessidades internas de desenvolvimento.

\footnotetext{
${ }^{5}$ Segundo a Declaração Ministerial na Ocasião do $40^{\circ}$ aniversário do Grupo dos 77, da Conferência das Nações Unidas Para o Comércio e o Desenvolvimento: “14.O processo de globalização e liberalização tem produzido efeitos não uniformes entre os países. As disciplinas e obrigações internacionais estão também crescentemente adotando regras que moldam as escolhas de políticas de desenvolvimento dos países em desenvolvimento.Estes progressos, que têm tido efeitos econômicos e sociais negativos, ressaltam a importância de se garantir o âmbito para políticas para países em desenvolvimento apresentarem objetivos de desenvolvimento nacional baseados nas suas necessidades de desenvolvimento, financeiras e de comércio".

${ }^{6} \mathrm{O}$ comércio internacional tem sido, hoje, considerado um dos principais motivadores da desigualdade entre países desenvolvidos e os subdesenvolvidos. (SENDAGUE, 1995, p. 144-145; e BEDJAOUI, Mohammed, 1991, p. 1199-1200)

${ }^{7}$ Vide: Doc. NU: E/CN.4/1995/11, 5 September 1994, Question of the realization of the right to development on its second session.
} 


\section{REGULAMENTAÇÃO NORMATIVA DO SISTEMA INTERNACIONAL DE COMÉRCIO - SUA EVOLUÇÃO E EFETIVIDADE HODIERNA}

A relação entre comércio e desenvolvimento é, portanto, reconhecida, no âmago das bases contemporâneas do sistema internacional de comércio, como inerente à dinâmica das transações comerciais internacionais. Sua regulamentação normativa torna-se, pois, indispensável, na medida em que, uma vez realizada democraticamente, esta conjuntura comercial servirá de meio ao alcance de uma ordem internacional justa e igualitária entre as nações.

Os diplomas normativos que regem o sistema internacional de comércio demonstram a já antiga preocupação da comunidade internacional quanto ao binômio comérciodesenvolvimento, buscando, ao menos teoricamente, coadunar o Sistema Internacional de Comércio à efetivação do desenvolvimento de cada Estado - devendo-se ter em conta, para tais fins, suas debilidades, hipossuficiências e fragilidades particulares, de modo a se concretizar um igualdade real, não apenas formal entre as nações.

Remonta à Carta de Havana, a primeira tentativa concreta de, no pós-Segunda Mundial, promover-se a realização cabal do direito ao desenvolvimento como conseqüência de um comércio internacional justo - a partir da menção ao pleno emprego e a atividades econômicas, ao desenvolvimento econômico, a práticas comerciais restritivas, a acordos intergovernamentais sobre produtos-base e resolução de diferendos, entre outros quesitos que revelavam sua ambição em normatizar um comércio internacional norteado à luz do desenvolvimento das nações.

Todavia, esta Carta não chegou a ser concretizada, vez que não obteve a aprovação do mínimo necessário de 20 signatários, notadamente pela não-ratificação pelos Estados Unidos da América.

Paralelamente, 23 países se reuniam na Conferência de Genebra ${ }^{8}$, na qual foram elaboradas reduções substanciais às barreiras comerciais. Tal conferência figura, historicamente, como a primeira grande rodada de negociações multilaterais de comércio, realizada sob a ciência de que as negociações bilaterais não mais se faziam suficientes à cooperação mundial, nem tampouco à garantia de almejados mercados consumidores.

Aproveitando, com algumas reformulações, parte do projeto da Carta de Havana - qual seja, o Capítulo IV, sobre política comercial -, tal Conferência resultou na criação do chamado GATT (General Agreement on Tariffs and Trade ou, em português, Acordo Geral sobre Pautas Aduaneiras e Comércio). O GATT entrou em vigor no dia $1^{\circ}$ de janeiro de 1948 e deveria regular o comércio internacional até a entrada em vigor da Carta de Havana. Não obstante, como esta não vigorou, o GATT fez-se regulador do comércio

\footnotetext{
${ }^{8}$ Ocorrida no ano de 1947, antes mesmo da reunião em Cuba, a Conferência de Genebra demonstrou a persistência das nações uma legislação regulamentadora do comércio internacional. Assim, tal conferência foi empreendida, em cuja estrutura se pode identificar a divisão em três partes principais, uma baseada em rascunho da Carta da OIC; outra referente à negociação de um acordo multilateral para a redução recíproca de tarifas; enquanto uma última centrava-se no deslinde da formulação de cláusulas passíveis de solucionar o dilemas das tarifas. Dava-se origem ao GATT, que entrou em vigor em janeiro de 1948.
} 
mundial, desde esta data até $1^{\circ}$ de Janeiro de 1995, quando entra em funcionamento a Organização Mundial do Comércio (OMC).

Completava-se, então, a tríade de instituições responsáveis por garantir a estabilidade econômica do período subseqüente à Segunda Guerra Mundial - GATT, Banco Internacional para a Reconstrução e Desenvolvimento (BIRD) e o Fundo Monetário Internacional (FMI). Instituições estas que foram originadas a partir da Conferência de Bretton Woods 9 .

Em seguida, conforme mencionado entra em vigor da OMC, em inícios de 1995, cuja instituição resultou de um complexo e prolongado processo envolvendo a comunidade internacional - que, após oito rodadas de negociações tarifárias e comerciais, chegava à Rodada Uruguai, na qual se deu a criação da OMC.

A OMC, cuja criação põe fim ao GATT como organismo regulador internacional, emerge, então, como a atual "base jurídica e institucional do sistema multilateral de comércio" (DO GATT à OMC: o que mudou, como funciona e para onde caminha o sistema multilateral de comércio, Documento de Internet), através da qual se inaugura inédita fase na dinâmica do comércio internacional, ao lançar as estruturas da política comercial contemporânea. Incorporando objetivos basilares da antiga GATT, os quais convergiam à consecução da redução de barreiras tarifárias, da liberalização comercial e do acesso aos mercados, a OMC ultrapassa as previsões normativas do acordo anterior, de fato lançando as vertentes normativas da Nova Ordem Econômica Internacional.

Assim, ainda que mantendo metas já dispostas no GATT, a nova organização internacional inclui, na agenda do comércio internacional, assuntos como o meio ambiente, investimentos internacionais, comércio de serviços, privilegiando, notadamente, a condução de políticas de desenvolvimento.

Desta feita, o binômio comércio-desenvolvimento foi contemplado pelas regras comerciais inauguradas com a atual organização reguladora do comércio internacional, notadamente quanto à previsão de políticas diferenciadas aos países ditos PEDs e PMDs. Com isto, busca-se promover uma democratização das relações comerciais internacionais, considerando-se as deficiências e peculiaridades de cada nação para fins de assegurar-lhes iguais condições comerciais, mediante o nivelamento jurídico.

Não obstante, o alcance e efetividade destas pretensões democratizantes, imiscuídas nos textos legais da OMC, restringem-se, quase em absoluto, ao campo teórico. As benesses contidas nestes textos legais não têm se concretizado na prática das negociações multilaterais, de modo que a estrutura política e institucional das economias internacionais têm se pautado conforme os interesses dos países mais influentes e economicamente favorecidos.

\footnotetext{
9 A Conferência de Bretton Woods "Os dois principais objetivos da Conferência foram, primeiro, avançar a redução das tarifas e outras barreiras ao comércio internacional e, segundo, criar uma estrutura global para minimizar os conflitos econômicos entre nações (...). A filosofia adjacente ao sistema é a teoria da vantagem comparativa que tinha sido desenvolvida pelos economistas britânicos David Ricardo e John Stuart Mill, ao aplicar a teoria de mercado de Adam Smith às transações internacionais" (MALANCZUK, 1996, p. 223).
} 
Como deficiências estruturais da OMC que corroboram e ilustram este entendimento, pode-se mencionar a adoção do "single undertaking"10, segundo o qual os países devem aderir aos acordos multilaterais de maneira integral, ou seja, adotando todas as cláusulas neles dispostas - o que reduz a possibilidade de os países membros da OMC escolherem quais os acordos dos quais participarem, inibindo, pois, sua capacidade de adoção de políticas desenvolvimentistas próprias a suas dificuldades e condições particulares.

Ademais, Os PEDs e PMDs também encontram dificuldades no fato de serem preteridos nos processos de tomada de decisão, os quais privilegiam, desmensuradamente, os Estados com representação em Genebra - únicos com voto e participação no Conselho Geral, órgão executivo da OMC.

Além disso, a categorização dos países em PEDs e PMDs não apresenta definição concreta e segura, não sendo realizada pela $\mathrm{OMC}$, mas sim submetendo-se ao crivo arbitrário e eivado de interesses políticos dos Estados-Membros, que, não raramente, interferem no processo de classificação destes países, para fins de conferir ou vetar as exceções reservadas aos PEDs e PMDs. ${ }^{11}$ Por estas razões acima esposadas, constata-se que as tentativas de promoção da igualdade formal não se têm concretizado, o que compromete, sobremaneira, a viabilidade de um justo e igualitário direito ao desenvolvimento a todas as nações devido, na mesma medida em que se verifica um déficit democrático na condução prática das políticas econômicas internacionais.

\section{O PRINCIPIO DA NÃO-DISCRIMINAÇÃO E A CNMF: MANDAMENTOS DE OTIMIZAÇÃO DO COMÉRCIO INTERNACIONAL EM FACE DO DIREITO AO DESENVOLVIMENTO}

A não-discriminação consiste no basilar princípio de todo o sistema multilateral de comércio inaugurado com as regras estabelecidas pelo sistema GATT/OMC. De fato, a importância de tal princípio é tamanha que o GATT e sua sucessora, a OMC, foram criadas com o intento principal de liberalizar o comércio internacional por intermédio da eliminação de dinâmicas comerciais que contrariem tal princípio e que, inevitavelmente, viessem, por via reflexa, a interferir no pleno desenvolvimento das nações prejudicadas. Este princípio encontra-se expressamente previsto em acordos GATT/OMC, nos quais manifesta-se, além da regra do tratamento nacional, também mediante a Cláusula da Nação Mais Favorecida (CNMF).

Ante a crescente importância e conseqüente regulamentação das relações econômicas internacionais, a níveis globais, a CNMF sobressai enquanto elemento tendente à concretização do princípio da não-discriminação, refletindo a consciência quanto à necessidade de implantação prática, nas relações comerciais modernas, da seguinte máxima: no comércio mundial, não deve haver tratamentos discriminatórios.

\footnotetext{
${ }^{10}$ No português, "Entendimento único".

11 Segundo Mônica Teresa Costa Souza, “A definição de país em desenvolvimento e páis menos desenvolvido é controversa. Não há indicadores específicos que possam ser utilizados para atribuir aos Estados essas categorias, ainda que a UNCTAD tenha criado um índice classificatório baseado na renda per capita a partir das modernas implicações do conceito de desenvolvimento; mesmo esse índice tem se mostrado insuficiente. O Índice de Desenvolvimento Humano (IDH), atribuído pelo PNUD parece ser mais adequado a essa classificação. (BARRAL; PIMENTEL, 2006).
} 
A CNMF, inscrita no artigo I do GATT ${ }^{12}$, determina que as partes contratantes, desde que membros da OMC, são obrigadas a se conceder, mutuamente, tratamento tão favorável quanto aquele dado a qualquer outra Parte-Contratante, na aplicação e administração dos direitos e impostos de importação e exportação de bens e serviços.

Basicamente, consiste, portanto, em uma multilateralização obrigatória de privilégios - de forma a garantir a extensão de qualquer concessão comercial a todas as partescontratantes.Como ensinamento doutrinário, previu-se que "in the GATT the MFN obligation calls for each contracting party to grant to every other contracting party the most favorable treatment that it grants to any country with respect to imports and exports of products, 13 (JACKSON, 1999, p. 157).

Destarte, a CNMF, inclusive reconhecida como "princípio da não-discriminação" (LUIZ, 2006, p. 43), figura, então, como uma das mais importantes regras da OMC. Atuando como verdadeiro alicerce do sistema inaugurado com a GATT, por promover, ao menos teoricamente, a liberalização, em bases igualitárias, do comércio internacional, a CNMF atua de forma a potencializar o caráter multilateral da OMC.

Enquanto uma das principais bases do Direito Internacional Público, a CNMF contribui, também, à afirmação da igualdade soberana dos Estados em face da política de comércio internacional - do que se pode inferir o evidente alcance que a efetiva aplicação de tal cláusula pode ter, dado seu caráter anti-discriminatório, sobre o desenvolvimento de uma nação. De fato, antes de sua implementação no âmbito da OMC, o Sistema Internacional de Comércio vinha caminhando contínua e progressivamente rumo a uma verdadeira fragmentação mundial das nações em blocos econômicos: com o aprofundamento de uma segmentação entre países do Norte e países do Sul, tendia-se cada vez mais a uma subordinação nefasta destes em relação aos interesses de dominação daqueles - visto que os países desenvolvidos, detentores dos mais avançados meios de produção e tecnologia, buscavam subjugar comercial, financeira e tecnologicamente os países tidos como pobres, subdesenvolvidos.

Essa tentativa de subordinação inelutavelmente ainda permanece, contudo, atentou-se para o fato de não haver uma relação unilateral de dependência do Terceiro Mundo em relação ao Primeiro; a relação inversa também é verdadeira ${ }^{14}$. Há, efetivamente, uma interdependência entre eles, dado que, conforme já afirmado, nenhuma nação, considerando-se o conjunto de suas necessidades, faz-se completamente auto-suficiente.

A OMC, regulando os acordos sobre o comércio e estabelecendo a extensão do tratamento conferido a uma nação mais favorecida, procurou reverter essa nefasta conjuntura de subordinação não apenas procurando eliminar a discriminação comercial formal, mas

12 Cláusula da Nação Mais Favorecida - Artigo I, GATT: - no comércio mundial não deve haver discriminação. Todas as partes contratantes têm que conceder a todas as demais partes o tratamento que concedem a um país em especial. Portanto, nenhum país pode conceder a outro vantagens comerciais especiais, nem discriminar um país em especial.

${ }^{13}$ Tradução livre: No âmbito do GATT, a CNMF exige que cada parte contratante garanta a cada outra parte contratante o tratamento mais favorável conferido a qualquer país, quanto à importação e exportação de produtos.

${ }^{14}$ Segundo a Declaração Ministerial na Ocasião do 40 aniversário do Grupo dos 77, de 12 de junho de 2004, da Conferência das Nações Unidas Para o Comércio e o Desenvolvimento: "28. O diálogo e as negociações do Norte-Sul exigem uma cooperação genuína para o desenvolvimento através da associação global." 
também aquela de cunho material - desde que esta não esteja devidamente excetuada por um dos casos previstos nos textos legais, notadamente as situações do artigo XX, da DDD. Neste conduto, vem, portanto, a figurar a CNMF, dado que, uma vez constatada a existência de uma medida discriminatória, gerar-se-ia, a partir de então, a presunção de não alinhamento para com o sistema OMC, justamente por atentar contra um de seus pilares o princípio da não-discriminação e, conseqüentemente, contra tal cláusula.

Contudo, a prática vem nos demonstrando que suplantar, concomitantemente, discriminações formais e materiais não tem sido tarefa de fácil realização. A base teórica da CNMF, segundo a qual todos os Estados gozarão da liberalização do comércio internacional em bases igualitárias, vem encontrando dificuldades em se adequar integral e eficazmente à realidade da economia global - marcada pelas diferenças, em termos de desenvolvimento, entre os Estados. Persistem, de fato, no seio da OMC, profundas deficiências no combate aos tratamentos discriminatórios verificados no âmbito fático ${ }^{15}$ que, muitas vezes, encontram-se mascarados através das exceções que acompanham a CNMF. Urge, então, uma premente revisão dos desdobramentos práticos que ora vêm sendo alcançados pela atual noção de desenvolvimento, a fim de que o verdadeiro significado deste - atingido com a consagração do direito ao desenvolvimento enquanto componente dos direitos humanos - reflita-se adequadamente no sistema multilateral de comércio.

O sustentável desempenho deste sistema depende da garantia de direito ao desenvolvimento às nações. Este, por sua vez, só será adequada e efetivamente garantido caso se encontre conjugado a uma política de não-discriminação. Deste modo, deve-se buscar transformar a CNMF em autêntico instrumento de concretização do principio da não-discriminação. Mas o principal desafio persistente reside em concretizar tal anseio no âmbito prático, não o restringindo ao campo meramente teorético.

\section{“REGRAS DO JOGO FAVORÁVEIS AO PARCEIRO MAIS FRACO”16}

Nesse contexto, duas questões devem ser postas em relevo quanto à realização do direito ao desenvolvimento no âmbito do comércio internacional: o Tratamento Especial e Diferenciado (TED) e a possibilidade de acesso aos mercados, entendimento também seguido por Mennicucci (OLIVEIRA, 2005, p. 691). Ambos devem, ao menos em tese, nortear as relações comerciais realizadas no exterior, já que os Estados são, segundo o parágrafo $2^{\circ}$. do artigo $4^{\circ}$. da DDD, incumbidos da

[...] ação permanente para promover um desenvolvimento mais rápido dos países em desenvolvimento. Como complemento dos esforços dos países em desenvolvimento, uma cooperação

\footnotetext{
${ }^{15}$ Segundo a Declaração Ministerial na Ocasião do 40 aniversário do Grupo dos 77, de 12 de junho de 2004, da Conferência das Nações Unidas Para o Comércio e o Desenvolvimento: “12. As expectativas de uma maior segurança global e de uma ordem econômica social internacional justa não foram realizadas. $\mathrm{O}$ mundo atual está tomado por problemas sociais e econômicos agudos, muitos dos quais de natureza estrutural". Disponível em: http://www.unctad.org/pt/docs/td405_pt.pdf

${ }^{16}$ MYRDAL, 2007, documento de Internet. Esta noção refere-se à urgência de um tal proceder no âmbito das relações econômicas internacionais, conforme será retomado mais adiante no texto.
} 
internacional efetiva é essencial para prover esses países de meios e facilidades apropriados para incrementar seu amplo desenvolvimento. (Declaração Sobre o Direito ao Desenvolvimento, 1986 , parágrafo $2^{\circ}$, art. $4^{\circ}$ ).

O último dos dois mencionados fatores se faz indispensável ao processo desenvolvimentista de qualquer nação, devendo, necessariamente, ser estendido a todos os países desejosos de participar do sistema internacional de trocas. Aceder ao mercado internacional é alargar o mercado consumidor, é potencializar as oportunidades de investimentos, é aumentar a produtividade e a especialização e também o progresso tecnológico da nação comerciante - confirmando-se, então o potencial e influência da faculdade de acesso ao mercado quanto à promoção do desenvolvimento de um país. Assim, garantir tal faculdade às nações, notadamente às mais pobres, faz-se função dos Estados atuantes no conjunto da economia mundial, permitindo-se que, em caráter excepcional, o acesso ao mercado pelos Países em Desenvolvimento (PED's) e dos Países Menos Desenvolvidos (PMD's) seja facilitado.

Quanto ao TED, este foi criado na Rodada Tóquio, pela decisão "Cláusula de Habilitação" "17. Seu texto data de 1979 e surge permitindo que a relação entre os países participantes da OMC seja relativizada de acordo com os diferentes graus de desenvolvimento dos mesmos, devendo ser dada atenção especial aos problemas e condições particulares dos Países Em Desenvolvimento (PEDs) e Países de Menor Desenvolvimento (PMDs). Sua importância reside, principalmente, no fato de estes países encontrarem grandes dificuldades em fazer prevalecer seus interesses e exigências no âmbito das decisões tomadas na OMC já que esta, apesar de ser considerada uma das mais democráticas organizações internacionais, nem sempre permite que a opinião de tais países seja considerada, conferindo, em geral, exclusivamente aos países com representação em Genebra, o direito de voto e de participação em seu Conselho Geral ${ }^{18}$.

Além disso, esse déficit democrático é ainda reforçado pelo sobremencionado sistema de entendimento único ("single undertaking") adotado pela OMC. Frise-se, conforme anteriormente explicitado, que, segundo este, os acordos multilaterais firmados no seio desta não podem ser adotados separadamente, mas apenas quando integralmente assumidos por todos os países-Membros - restando aos PED's e PMD'S, então, a mera possibilidade de escolha quanto aos acordos dos quais queiram tomar parte, e não quanto a sua elaboração, o que de fato compromete a viabilidade de políticas nacionais de desenvolvimento que estejam em dissonância com tais acordos uniformemente adotados.

O crescimento das desigualdades internacionais deve-se, em grande parte, a um sistema econômico mundial injusto e à manutenção de certo imperialismo, dada a dominação econômica estrangeira. A colonização direta praticamente desapareceu nos anos 60, mas foi substituída por uma colonização ainda mais perniciosa: a colonização econômica. Hoje,

\footnotetext{
${ }^{17}$ No inglês Enabling Clause. Vide a íntegra da decisão em: “Differential and More Favourable Treatment Reciprocity and Fuller Participation of Developing Countries, decisão de 28 de novembro de 1979 (L/4903)" Disponível em: http://www.worldtradelaw.net/tokyoround/enablingclause.pdf.

18 A falta de representação ou a representação precária dos países em desenvolvimento em Genebra, prejudica seriamente a sua capacidade de participar dos progressos da OMC.
} 
os instrumentos e estruturas que reforçam este processo são, principalmente, o Banco Mundial, o Fundo Monetário Internacional (FMI) e, mais recentemente, os acordos da Organização Mundial do Comércio. Indícios dessa corrente realidade - marcada por uma verdadeira transferência de recursos do Sul em direção ao Norte, o que impede o pleno desenvolvimento daquele - refletem-se na necessidade de tomada de decisões justas a ambos os hemisférios do globo.

Segundo Gunnar Myrdal, "eqüidade nas relações econômicas internacionais exige regras do jogo favoráveis ao parceiro mais fraco" (MYRDAL, 2007, documento de Internet). Assim, a fim de se construir uma estrutura de comércio internacional equânime capaz de beneficiar tanto aos países ricos como aos pobres e, de tal forma, contornar a díspare realidade ora vigente, imprescindível se torna o fomento à realização das medidas retratadas - o acesso ao mercado e a TED: medidas primordialmente voltadas a um dever de cooperação para com o hipossuficiente desenvolvimento típico das nações em desenvolvimento.

Assim, tais se tornam instrumentos indispensáveis ao alcance da efetivação do direito ao desenvolvimento porque, a fim de que esteja conciliado com a promoção deste, o desempenho do Sistema Internacional de Comércio deve ser pautado por um modelo eqüitativo de governança.

Conforme observa o ex-secretário de Estado dos EUA, Colin Powell, "entre nossas outras prioridades [as do governo americano], nada é mais importante do que a promoção do comércio internacional" e continua, justificando, "o comércio internacional cria riquezas" (Colin Powell, 2007, Documento de Internet). Contudo, tais riquezas não podem ficar nefasta e discriminatoriamente restritas aos países desenvolvidos. A própria DDD reforça a premente necessidade de revisão das práticas comerciais internacionais, em seu preâmbulo, ao mostrar-se ciente de que os esforços a nível internacional para promover e proteger os direitos humanos devem ser acompanhados de esforços para estabelecer uma nova ordem econômica internacional.

Para tanto, torna-se indispensável a consecução de uma substancial mudança na vigente estrutura do comércio internacional, notadamente quanto aos tratamentos discriminatórios que suas repercussões persistem em provocar. Empregando e, então, validando cláusulas de não-discriminação e medidas de aplicação práticas e eficazes de distribuição igualitária de riquezas, os atores do sistema de comércio internacional poderão, enfim, tornar viável o alcance do objetivo teórico inicialmente perquirido pelos idealizadores desse comércio: uma expansão do fluxo de capitais entre as nações que seja capaz de promover o bem-estar dos povos mediante um efetivo e democrático aumento de sua renda real - e, destarte, tornar, enfim, possível a coexistência entre o Sistema Internacional de Comércio e o Direito ao Desenvolvimento.

\section{CONSIDERAÇÕES FINAIS}

Sob a denominação "Sistema Internacional de Comércio e Direito ao Desenvolvimento: coexistentes ou antagônicos?", o presente trabalho voltou-se à compreensão deste sistema, 
buscando avaliar as nuances e implicações inerentes à justa e democrática concretização de uma tal inter-relação.

Percebe-se, hodiernamente, que a conciliação entre comércio e desenvolvimento tem sido obstaculizada ante a dinâmica capitalista de busca incessante por lucros e reforçada pelas deficiências estruturais da OMC - que corroboram e aprofundam o distanciamento entre países desenvolvidos e aqueles carentes de um nível de desenvolvimento suficientemente elevado para beneficiarem-se das relações comerciais internacionais de forma igualitária. $\mathrm{O}$ desenrolar fático dos acontecimentos históricos tem comprovado, pois, que os instrumentos reguladores do sistema multilateral de comércio utilizam o desenvolvimento como legitimação de seu discurso; enquanto, na prática, sua efetivação não se concretiza.

Medidas tipificadas como ilegais no âmbito do comércio internacional seguem continuamente praticadas, notadamente quanto aos subsídios governamentais e à proteção à indústria nacional - o que é utilizado, preponderantemente, pelos países que hoje detêm elevado grau de industrialização.

Como tais deficiências, pode-se mencionar a medida do "single undertaking", segundo o qual os países devem aderir aos acordos multilaterais de maneira integral, ou seja, adotando todas as cláusulas neles dispostas - o que reduz a possibilidade de os países membros da OMC escolherem quais os acordos dos quais participarem, inibindo, pois, sua capacidade de adoção de políticas desenvolvimentistas próprias a suas dificuldades e condições particulares.

Ademais, Os PEDs e PMDs também encontram dificuldades no fato de serem preteridos nos processos de tomada de decisão, os quais, na prática, privilegiam, desmesuradamente, os Estados com representação em Genebra - únicos com voto e participação no Conselho Geral, órgão executivo da OMC.

Igualmente, a categorização dos países em PEDs e PMDs não apresenta definição concreta e segura, não sendo realizada pela $\mathrm{OMC}$, mas sim submetendo-se ao crivo arbitrário e eivado de interesses políticos dos Estados-Membros.

A estrutura atual de regulamentação comercial revela, na prática, uma invasividade no campo normativo e decisório das autoridades nacionais e dos ordenamentos jurídicos internos, pelas políticas e normas votadas em um foro internacional e externo aos Estados, no que se reverte em uma limitação à possibilidade de condução de políticas públicas pelos Estados dependentes, vez que devem conformar-se, direta ou indiretamente, aos interesses das potências econômicas.

Constata-se, pois, um déficit democrático na condução prática das políticas econômicas internacionais. Não basta a formulação teórica de pretensões idílicas de conformação do comércio internacional à promoção do desenvolvimento, urge a instauração efetiva de um sistema de governança eqüitativo, pelo qual o fim desenvolvimentista possa ser assegurado através da participação igualitária, da realização de processos justos e da concretização da igualdade material, pelo que se considere as condições peculiares e deficitárias de cada Estado-Membro, preservando-lhes, assim, espaço para a adoção de políticas públicas próprias de desenvolvimento nacional. 
O desenvolvimento não é interesse apenas dos PEDs e PMDs, mas sim de todas as pessoas e nações individualmente consideradas, considerando-se a crescente interdependência mundial - indissociável à conjuntura globalizada da época contemporânea.

\section{REFERÊNCIAS}

1. ABI-SAAB, Georges. Le droit au dévelopement. In :ANNUAIRE SUISSE DE DROIT INTERNATIONAL. Suíça: [s.n.], 1988. p. 12. v. 64.

2. BARRAL, Welber; PIMENTEL, Luiz Otávio (Orgs). Comércio internacional e desenvolvimento. Florianópolis: Fundação Boiteux, 2006.

3. BEDJAOUI, Mohammed. The right to development. In: International Law: Achievements and Prospects. [S.1.: s.n.]. 1991. p. 1199-1200.

4. BONAVIDES, Paulo. Curso de direito constitucional. 13. ed. São Paulo: Malheiros Editores, 2003.

5. BOSON, Gerson de Britto Mello. Direito internacional público: o estado em direito das gentes. 3. ed. Belo Horizonte: Del Rey, 2000.

6. COLLIARD, Claude Albert. L'adoption par l'assembléss générale de la déclaration sur le droit au développement, 4 décembre 1986. In: Annuaire Français de Droit International, França. [s.n.], 1987. v.33.

7. CUBA: DRAFT RESOLUTION. Necessity of ending the economic, commercial and financial embargo imposed by the United States of America against Cuba. Disponível em:

<http://www.eyeontheun.org/assets/attachments/documents/5704.doc. > Acesso em 22 jun. 2009.

8. DECLARAÇÃO sobre o direito ao desenvolvimento. Disponível em:

<http://www.dhnet.org.br/direitos/sip/onu/spovos/lex170a.htm> Acesso em: 01 out 2008.

9. "Differential and More Favourable Treatment Reciprocity and Fuller Participation of Developing Countries, decisão de 28 de novembro de 1979 (L/4903)". Disponível em:

<http://www.worldtradelaw.net/tokyoround/enablingclause.pdf.> Acesso em 22 jun. 2008.

10. DI SENA JUNIOR, Roberto. Comércio internacional e OMC: a cláusula social na OMC. Curitiba: Juruá, 2003.

11. DUPAS, Gilberto (Coord). América Latina no início do século XXI: perspectivas econômicas, sociais e políticas. Rio de Janeiro/ São Paulo: Editora da Unesp e Instituto de Estudos Econômicos e Internacionais, 2005.

12. FIETTA, Stephen. Most favoured nation treatment and dispute resolution under bilateral investment treaties: a turning point?. In: International Arbitration Law

13. KANT, I. A Paz perpétua e outros opúsculos. 7. ed. Trad. Artur Mourão. Lisboa: [s.n.], 2002.

14. KELSEN, Hans. Direito internacional e estado soberano. Organização de Mario G. Losano e Tradução de Marcela Varejão. São Paulo: Martins Fontes, 2002. 
15. MALANCZUK, Peter. Akehurst's Modern introduction to international law. 7. ed. [S.1.]: Routledge, 1996. p. 223.

16. MONTESQUIEU, C. L. de S. O espírito das leis. Tradução Fernando Henrique Cardoso e Leôncio Martins Rodrigues. Brasília: Universidade de Brasília, 1982. 